Research Article

\title{
Correlation between obesity and successful ovulation induction with Clomiphene citrate
}

\author{
Rida Eka Setiani ${ }^{1}$, Sri Ratna Dwiningsih ${ }^{2 *}$, Gadis Meinar Sari ${ }^{3}$ \\ 1) Midwifery Student, Faculty of Medicine, Universitas Airlangga, Surabaya, Indonesia \\ 2) Department of Obstetrics and Gynecology, Faculty of Medicine, Universitas Airlangga - Dr.Soetomo General Hospital, \\ Surabaya, Indonesia \\ 3) Department of Physiology, Faculty of Medicine, Universitas Airlangga, Surabaya, Indonesia
}

\section{A R T I C L E I N F O}

$\begin{array}{ll}\text { Submitted } & : 28^{\text {th }} \text { May } 2021 \\ \text { Accepted } & : 2^{\text {nd }} \text { August } 2021 \\ \text { Published } & : 25^{\text {th }} \text { January } 2022\end{array}$

Keywords:

ovulation induction, clomiphene citrate, obese

\section{*Correspondence: \\ sri-r-d@fk.unair.ac.id}

This is an Open acces article under the CC-BY license

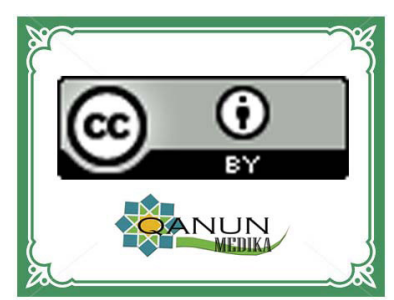

\section{ABSTRACT}

Ovulation induction with clomiphene citrate is a hormonal therapy for infertile women with impaired ovarian function caused by dysregulation of the hypothalamus and pituitary, affecting egg development and ovulation. Several factors, such as obesity, influence the success rate of treatment with clomiphene citrate. According to the Asia-Pacific classification, obesity was classified into two categories, obesity type I (25-29,9 kg/m $)$ and obesity type II ( $\geq 30 \mathrm{~kg}$ / $\mathrm{m}^{2}$ ). The success rate of ovulation induction with clomiphene citrate in obese infertile women at Graha Amerta Fertility Clinic in Dr. Soetomo General Hospital on July 2019 July 2020 was about $22.8 \%$. The research aimed to analyze the correlation between obesity with successful ovulation induction with clomiphene citrate. This research method was observational analytic research with a cross-sectional approach. The data were collected from medical records of infertile obese women who undergo ovulation induction with clomiphene citrate. According to inclusion criteria, the number of samples is 79 cycles of infertile obese women who undergo ovulation induction with clomiphene citrate. Data analysis using Chi-square test. The result showed that successful ovulation induction in obese type I was $17.7 \%$ and in obese type II was $5.1 \%$. There was a correlation between obesity with successful ovulation induction with clomiphene citrate $(p=0.009)$. In conclusion, there was a correlation between obesity with successful ovulation induction. 


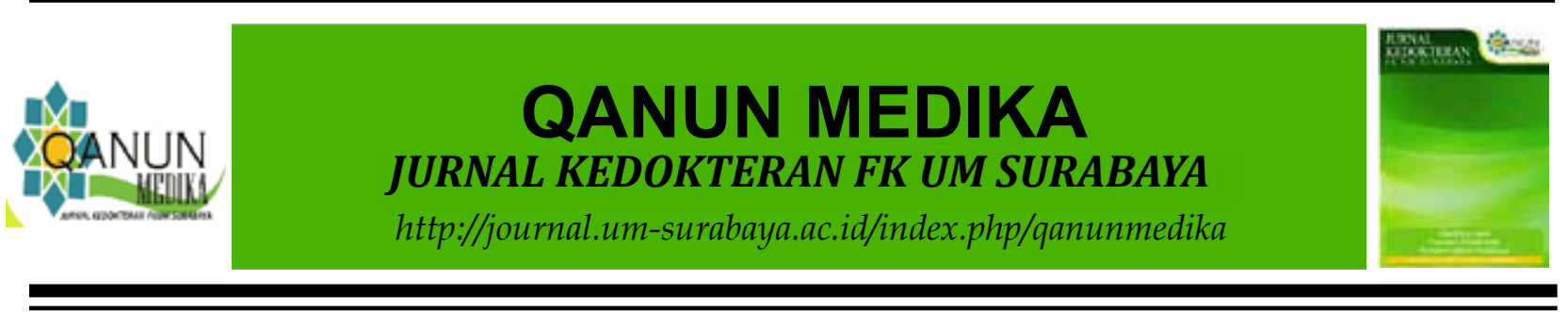

\section{INTRODUCTION}

World Health Organization (WHO) describes infertility as the failure to achieve a pregnancy after one year (or more) of regular unprotected sexual intercourse. In Indonesia, infertility affects $10-15 \%$ of couples of reproductive age (Harzif et al., 2019). Etiologies of Infertility caused by ovulatory dysfunction (21-25\%), tubal factors $(14-20 \%)$, male factors $(30 \%)$, and pelvic or uterine abnormalities (10-13\%). Ovulation induction is commonly used to treat infertility, specifically anovulation (Lindsay \& Vitrikas, 2015). Ovulation induction uses a variety of hormone-based medications. The first-line treatment of patients with anovulation is clomiphene citrate (CC). It is inexpensive, user-friendly because orally administered and doesn't require much monitoring.

Ovulation induction with clomiphene citrate is a hormonal therapy for infertile women with impaired ovarian function caused by dysregulation of the hypothalamus and pituitary, which stimulates egg development and ovulation (Speroff \& Fritz, 2012). CC is a selective estrogen receptor modulator (SERM) that has been first line treatment for patient with oligomenorrhea or anovulation more than 40 years. CC mechanism is competing for endogenous estrogen receptors in the hypothalamus and pituitary, reducing negative feedback signaling of natural estrogen. CC binds the hypothalamus longer than natural estrogen, thus making block of the replenishment estrogen receptors. This effect makes the body believe that estrogen level is low, which triggers activation of neuroendocrine to increase release of gonadotropin FSH secretion (Mesiano \& Jones, 2017).

CC dosage varies with body weight. Nevertheless, there is no reliable way to predict what dosage will be required in individual women accurately. There are several different management protocols and techniques for $\mathrm{CC}$ to allow flexibility and customization of treatment for each patient and provider (Lindheim et al., 2018).

The medications start with a dose $50 \mathrm{mg}$ for 5 days, beginning on day $2-5$ of the menstrual cycle or a progestogen-induced menstrual bleed. If ovulation has not occurred, $\mathrm{CC}$ dose may be increased up to the maximum dose reached $150 \mathrm{mg}$ or ovulation has occurred (Brown J \& Hughes, 2009). Ovulation is expected to occur between day 5-10 after the last $\mathrm{CC}$ dose. The success rate of ovulation induction with $\mathrm{CC}$ was almost $70-80 \%$ of patients, and $40-50 \%$ will conceive after six cycles (Balen, 2013). Possibility response decrease is influenced by several factors, such as obesity (Speroff \& Fritz, 2012).

Obesity is a common problem among women of reproductive age and is defined as abnormal excessive fat accumulation that negatively affects health (WHO, 2020). According to the Asia-Pacific classification, obesity was classified into two categories, obesity type I $\left(25-29,9 \mathrm{~kg} / \mathrm{m}^{2}\right)$ and obesity type II $(\geq 30 \mathrm{~kg} /$ $\mathrm{m}^{2}$ ) (Nishida et al., 2004). In obesity, some mechanisms can affect ovulation induction, including increased peripheral aromatization to estrogen, hyperinsulinemia, insulin resistance and hyperleptinemia (Speroff \& Fritz, 2012; Oliveira \& Lemos, 2010). Obesity also increases the volume distribution of drugs, increasing the total amount of drugs required for the equivalent action at the target organ (Akpinar et al., 2016). All of these factors related to obesity can negatively impact ovulation induction.

In Indonesia, research rarely discusses clomiphene citrate, mainly when it is associated with obesity. This study aims to analyze the relationship between obesity and successful ovulation induction with clomiphene citrate. 


\section{METHODS}

This research method is observational analytic with a cross-sectional approach and total sampling technique. The independent variable is obesity, and the dependent variable is successful ovulation induction. This study enrolled 31 obese infertile women with 79 cycles of ovulation induction with $\mathrm{CC}$ at Graha Amerta Fertility Clinic in Dr. Soetomo General Hospital from July 2019 - July 2020. The samples in this study were selected according to inclusion criteria. The inclusion criteria of this study were:

1. Obese infertile women who undergo ovulation induction with clomiphene citrate for timed intercourse or intrauterine insemination program

2. The medical record that has ovulation data for each cycle of ovulation induction

Body mass index (BMI) was measured with weight in kilograms divided by the square of height in meters. This study used BMI according to the Asia-Pacific classification because there is evidence that the association between BMI, percentage, and body fat distribution differs between populations. In some Asian populations, a specific BMI reflects a higher rate of body fat than in the white or European population. Obesity was classified into two categories, namely, obesity type I (25$\left.29,9 \mathrm{~kg} / \mathrm{m}^{2}\right)$ and obesity type II $\left(\geq 30 \mathrm{~kg} / \mathrm{m}^{2}\right)$ (Nishida et al., 2004).

$\mathrm{CC}$ induction protocol started with a dose 50 $\mathrm{mg}$ (which was increased to 100 and $150 \mathrm{mg}$ in subsequent cycles in case of absence of ovulation) from day 2-5 of menstrual cycles. Once ovulation has occurred, there should be no increasing $\mathrm{CC}$ dose. It started from 31 cycles with $50 \mathrm{mg}$ dose, 4 cycles were success. Dose increased to $100 \mathrm{mg}$ for the remaining 27 cycles, and 6 cycles were success. The remaining 21 cycles who did not respond used doses up to $150 \mathrm{mg}$, and 8 cycles were successful.

Response to ovulation induction with CC were assessed by ovulation. Ovulation was verified by ultrasonography of preovulation follicle size on day 11 up to day 14 cycles greater than 18 $\mathrm{mm}$ or the presence of pregnancy. The data were collected and coded then entered into SPSS version 25.0 for windows. Data were analyzed using Chi-square test. The Health Research Ethics Committee section of Dr. Soetomo General Hospital has approved and certified this research with ethical letter number 0036/ LOE/301.4.2/II/2021.

\section{RESULT}

Table 1 shows the characteristics of the study population. This study enrolled 31 obese infertile women with a total of 79 cycles. The age of study population $<35$ years were $20(64.5 \%)$ and $>35$ years $11(35.5 \%)$. Of 31 patients reported experiencing primary infertility were $28(90.3 \%)$ and secondary infertility $3(9.7 \%)$. The number of cycles from infertile obese women who successfully ovulation induction with $\mathrm{CC}$ were 18 cycles (22.8\%), 14 cycles $(17.7 \%)$ was obesity type I and $4(5.1 \%)$ were obesity type II.

Table 2 shows the relationship between type obesity and successful ovulation induction using the Chi-square test. There was a significant relationship between obesity and successful ovulation induction $\mathrm{p}=0.009$. 


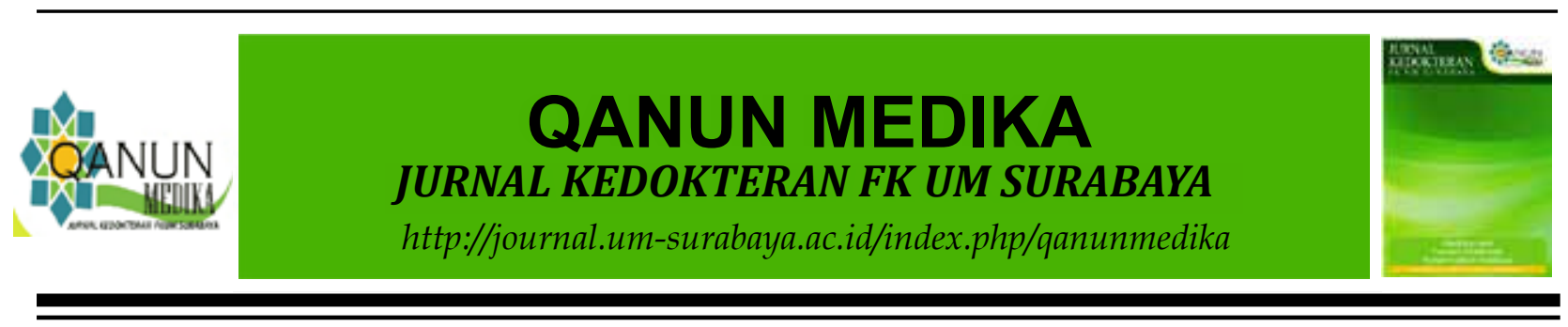

Table 1. Characteristics of Study Population

\begin{tabular}{lcc}
\hline \multicolumn{1}{c}{ Variable } & N & $\mathbf{\%}$ \\
\hline Age (years) & & \\
1. $\quad<35$ & $20 / 31$ & 64.5 \\
2. $>35$ & $11 / 31$ & 35.5 \\
\hline Type of Infertility & & \\
1. Primary infertility & $28 / 31$ & 90.3 \\
2. Secondary Infertility & $3 / 31$ & 9.7 \\
\hline Obesity & & \\
1. Obesity Type I & $40 / 79$ & 50.6 \\
2. Obesity Type II & $39 / 79$ & 49.4 \\
\hline Successful Ovulation Induction & & \\
1. Responders & $18 / 79$ & 22.8 \\
2. Non-Responders & $61 / 79$ & 77.2 \\
\hline
\end{tabular}

Table 2. Chi-square test between Obesity and Successful Ovulation Induction

\begin{tabular}{|c|c|c|c|c|c|c|c|c|}
\hline & & \multicolumn{4}{|c|}{$\begin{array}{l}\text { Successful ovulation } \\
\text { induction }\end{array}$} & \multirow{2}{*}{\multicolumn{2}{|c|}{ Total }} & \multirow{3}{*}{$P$ value } \\
\hline & & \multicolumn{2}{|c|}{ Responders } & \multicolumn{2}{|c|}{$\begin{array}{c}\text { Non- } \\
\text { Responders }\end{array}$} & & & \\
\hline & & $\mathrm{N}$ & $\%$ & $\mathrm{~N}$ & $\%$ & $\mathrm{~N}$ & $\%$ & \\
\hline \multirow[b]{2}{*}{ Obesity } & Obesity Type I & 14 & 17.7 & 26 & 32.9 & 40 & 50.6 & \multirow[b]{2}{*}{0.009} \\
\hline & Obesity Type II & 4 & 5.1 & 35 & 44.3 & 39 & 49.4 & \\
\hline Total & & 18 & 22.8 & 61 & 77.2 & 79 & 100 & \\
\hline
\end{tabular}

\section{DISCUSSION}

A total of 79 cycles from 31 obese infertile women medical records have been verified as inclusion data from this study. This study found that most responders are the cycles from obesity type I $\left(B M I=25-29,9 \mathrm{~kg} / \mathrm{m}^{2}\right)$. These results are consistent with research conducted by Ellakwa et al., (2016). This study explains that women with higher BMI $\left(\geq 30 \mathrm{~kg} / \mathrm{m}^{2}\right)$ were less likely to respond to clomiphene citrate. Another study by Aboul et al. (2004). also showed that BMI was significantly higher in CC non-responders patients. These findings indicate that increasing BMI also increases the risk of failure of ovulation induction with $\mathrm{CC}$.

This study demonstrates a significant correlation between obesity and successful ovulation induction with $\mathrm{CC}(\mathrm{p}=0.009)$, which is supported by previous reports from Aboul et al., (2004), who found a correlation between obesity and successful ovulation induction with $\mathrm{CC}(\mathrm{p}=<0.001)$ and information from Ellakwa et al., (2016).with $(\mathrm{p}=0.001)$.

There is evidence that obesity affects ovulation induction. Obese women tend to respond poorly to ovulation induction with CC (Imani et al., 1999).This impact occurred because obesity 
is a predisposing factor of several hormonal changes that play important roles in ovulation, including increased peripheral aromatization to estrogen, hyperinsulinemia, insulin resistance, and hyperleptinemia.

Increased peripheral aromatization to estrogen occurred due to increase the ability of adipose tissue to accumulate sex hormones within adipocytes and interconvert androgens to estrogen through local enzymatic reactions, resulting in elevated estrogen concentrations, which causes negative feedback in the hypothalamus and pituitary, resulting in decreased FSH and anovulation (Oliveira \& Lemos, 2010; Rosenfield \& Ehrmann, 2016)). Hyperinsulinemia may happen in obese women because increased of body fat changes the sensitivity and pattern secretion of insulin. High levels of insulin can decrease levels of hepatic sex hormone-binding globulin (SHBG) production, resulting in increased levels of free estrogen and testosterone (Speroff \& Fritz, 2012). Hyperinsulinemia is also associated with hyperandrogenemia; high insulin levels stimulate androgen synthesis in theca cells, resulting in high local androgen production, which may inhibit ovulation by premature follicular atresia (Nelson \& Fleming, 2007). Leptin concentrations are also associated with the amount of adipose tissue so that higher leptin concentrations can be found in obese women. Increased leptin concentrations disrupted follicular development and oocyte maturation (Moschos et al., 2002).

A Study from University of Alexandria, Egypt, showed that women with obesity, hyperandrogenemia, hyperinsulinemia, and high leptin concentrations tend to respond poorly to ovulation induction with CC (Aboul et al., 2004). Obesity also increases the volume distribution of drugs, which increases the total amount of drugs required for the equivalent action at the target organ (Akpinar et al., 2016). Consequently, a higher dose of CC would be required in obese patients compared to nonobese. All of these factors related to obesity can negatively impact ovulation induction with CC.

These study findings have a different result from the Uniformed Services University of Health Sciences, United States, suggesting that $\mathrm{CC}$ responders were more obese than nonresponders. This occurred because body mass index may not be the most accurate predictor of ovulatory response to CC. This study suggests that the relevant predictor's response was elevated fasting insulin levels in patients who failed to CC (Armstrong et al., 1996). Imani et al., (2000) have designed a nomogram to predict ovulation induction based on patient characteristics. These characteristics contain BMI calculations; calculating BMI is expected to enhance the effectiveness of treatment and cost. Also, BMI can estimate the weight loss needed to improve the responses of ovulation induction. Another study by (2011) revealed that BMI is a predictor of response to ovulation induction agents. Lifestyle modifications and weight loss should always be offered to patients with obesity. Weight loss of $5-10 \%$ can cause spontaneous ovulation or increase the response of ovulation induction with CC (Legro et al., 2015).

There are several limitations to this study. First, we evaluated BMI based on the medical record. Therefore our sample size depends on the completeness of data written on the medical record. Second, we could not demonstrate the association between obesity and several hormonal changes that may affect ovulation induction. The only parameter in this study was BMI. Therefore, future research might need other parameters such as insulin resistance, androgen, and serum leptin to demonstrate this relation. Also, this study has a potential bias caused by the fact that each patient could have more than one cycle with a different dose in every treatment. But, with multiple checks of 


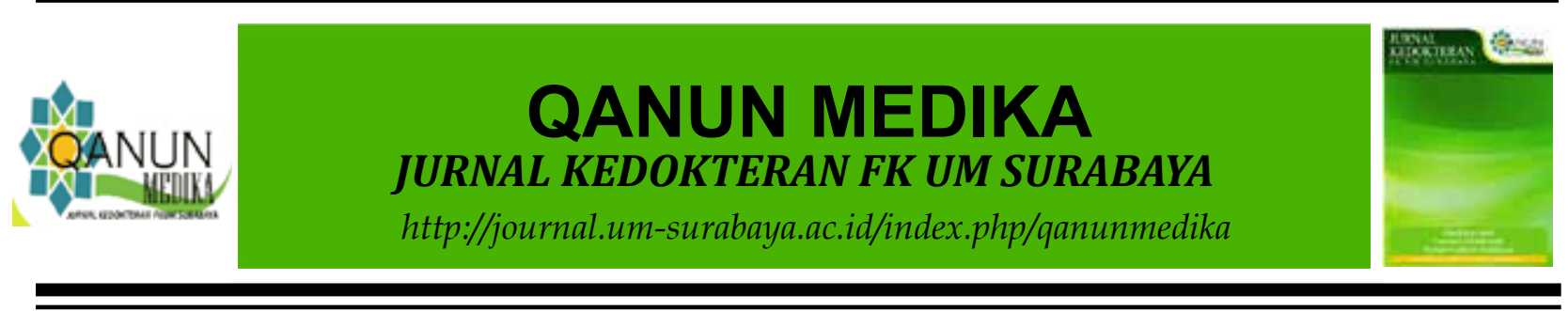

the data, we believed we could prevent bias. However, this study is retrospective; a further prospective study is necessary to confirm our result.

\section{CONCLUSION}

There was a correlation between obesity and successful ovulation induction with clomiphene citrate. Since obesity may affect ovulation induction, evaluating body mass index parameters is very relevant for infertile women who undergo ovulation induction. Our study suggests that losing weight before starting ovulation induction would improve their reproductive outcomes.

\section{REFERENCES}

Aboul, W. M., Barghash, N. A., \& Ali, M. (2004). Clinical, ultrasonographic and endocrine predictors of ovarian response to clomiphene citrate in normogonadotropic anovulatory infertility. Middle East Fertility Society. https://tspace.library.utoronto.ca/ handle/1807/7458

Akpinar, F., Dilbaz, B., Cirık, D. A., Yilmaz, S., Kiykac, S., Karahanoglu, E., \& Mollamahmutoglu, L. (2016). The significance of anthropometric and endocrine parameters in ovulation induction with clomiphene citrate in women with polycystic ovary syndrome. Saudi Medical Journal, 37(11), 1272-1275. https://doi.org/10.15537/ smj.2016.11.15006

Armstrong, A. B., Hoeldtke, N., Wiess, T. E., Tuttle, R. M., \& Jones, R. E. (1996). Metabolic parameters that predict response to clomiphene citrate in obese oligo-ovulatory women. Military Medicine, 161(12), 732-734. https://doi. org/10.1093/milmed/161.12.732
Balen, A. H. (2013). Ovulation induction in the management of anovulatory polycystic ovary syndrome. Molecular and Cellular Endocrinology, 373(1), 77-82. https:// doi.org/https://doi.org/10.1016/j. mce.2012.10.008

Brown J, F. C. B. J. B. C., \& Hughes, E. (2009). Clomiphene and anti-oestrogens for ovulation induction in PCOS. Cochrane Database of Systematic Reviews, 4. https:// doi.org/10.1002/14651858.CD002249. pub4

Ellakwa, H. E., Sanad, Z. F., Hamza, H. A., Emara, M. A., \& Elsayed, M. A. (2016). Predictors of patient responses to ovulation induction with clomiphene citrate in patients with polycystic ovary syndrome experiencing infertility. International Journal of Gynecology and Obstetrics, 133(1), 59-63. https://doi.org/10.1016/j. ijgo.2015.09.008

Harzif, A. K., Santawi, V. P. A., \& Wijaya, S. (2019). Discrepancy in perception of infertility and attitude towards treatment options: Indonesian urban and rural area. Reproductive Health, 16(1), 126. https:// doi.org/10.1186/s12978-019-0792-8

Imani, B., Eijkemans, M. J. C., de Jong, F. H., Payne, N. N., Bouchard, P., Giudice, L. C., \& Fauser, B. C. J. M. (2000). Free Androgen Index and Leptin Are the Most Prominent Endocrine Predictors of Ovarian Response during Clomiphene Citrate Induction of Ovulation in Normogonadotropic Oligoamenorrheic Infertility1. The Journal of Clinical Endocrinology \& Metabolism, 85(2), 676-682. https://doi.org/10.1210/ jcem.85.2.6356

Imani, B., Eijkemans, M. J. C., te Velde, E. R., Habbema, J. D. F., \& Fauser, B. C. J. M. (1999). Predictors of Chances to Conceive in Ovulatory Patients during Clomiphene 
Citrate Induction of Ovulation in Normogonadotropic Oligoamenorrheic Infertility1. The Journal of Clinical Endocrinology \& Metabolism, 84(5), 1617-1622. https://doi.org/10.1210/ jcem.84.5.5705

Johnson, N. P., Bontekoe, S., \& Stewart, A. W. (2011). Analysis of factors predicting success of metformin and clomiphene treatment for women with infertility owing to PCOS-related ovulation dysfunction in a randomised controlled trial. Australian and New Zealand Journal of Obstetrics and Gynaecology, 51(3), 252-256. https://doi.org/10.1111/j.1479828X.2011.01295.x

Legro, R. S., Dodson, W. C., Kris-Etherton, P. M., Kunselman, A. R., Stetter, C. M., Williams, N. I., Gnatuk, C. L., Estes, S. J., Fleming, J., Allison, K. C., Sarwer, D. B., Coutifaris, C., \& Dokras, A. (2015). Randomized controlled trial of preconception interventions in infertile women with polycystic ovary syndrome. Journal of Clinical Endocrinology and Metabolism, 100(11), 4048-4058. https:// doi.org/10.1210/jc.2015-2778

Lindheim, S. R., Glenn, T. L., Smith, M. C., \& Gagneux, P. (2018). Ovulation Induction for the General Gynecologist. Journal of Obstetrics and Gynecology of India, 68(4), 242-252. https://doi.org/10.1007/ s13224-018-1130-8

Lindsay, T. J., \& Vitrikas, K. R. (2015). Evaluation and treatment of Infertility. American Family Physician, 91(5), 308314.
Moschos, S., Chan, J. L., \& Mantzoros, C. S. (2002). Leptin and reproduction: A review. Fertility and Sterility, 77(3), 433-444. https://doi.org/10.1016/S00150282(01)03010-2

Nelson, S. M., \& Fleming, R. (2007). Obesity and reproduction: Impact and interventions. In Current Opinion in Obstetrics and Gynecology (Vol. 19, Issue 4, pp. 384-389). https://doi.org/10.1097/ GCO.0b013e32825e1d70

Nishida, C., Barba, C., Cavalli-Sforza, T., Cutter, J., Deurenberg, P., Darnton-Hill, I., Deurenberg-Yap, M., Gill, T., James, P., Ko, G., Kosulwat, V., Kumanyika, S., Kurpad, A., Mascie-Taylor, N., Moon, H. K., Nakadomo, F., Nishida, C., Noor, M. I., Reddy, K. S., ... Zimmet, P. (2004). Appropriate body-mass index for Asian populations and its implications for policy and intervention strategies. The Lancet, 363(9403), 157-163. https://doi. org/10.1016/S0140-6736(03)15268-3

Oliveira, F. R. de, \& Lemos, C. N. C. D. (2010). Obesidade e reprodução. Femina. http:// files.bvs.br/upload/S/0100-7254/2010/ v38n5/a004.pdf

Rosenfield, R. L., \& Ehrmann, D. A. (2016). The Pathogenesis of Polycystic Ovary Syndrome (PCOS): The hypothesis of PCOS as functional ovarian hyperandrogenism revisited. In Endocrine Reviews (Vol. 37, Issue 5, pp. 467-520). Endocrine Society. https://doi. org/10.1210/er.2015-1104 